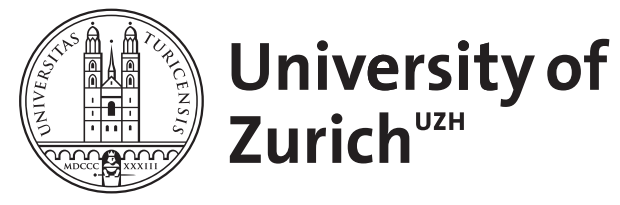

Zurich Open Repository and Archive

University of Zurich

University Library

Strickhofstrasse 39

CH-8057 Zurich

www.zora.uzh.ch

Year: 2005

Tick-borne meningo-encephalitis in a 6-week-old infant

Iff, Tobias ; Meier, Roland ; Olah, Eva ; Schneider, Jacques F L ; Tibussek, Daniel ; Berger, Christoph

DOI: https://doi.org/10.1007/s00431-005-1753-5

Posted at the Zurich Open Repository and Archive, University of Zurich

ZORA URL: https://doi.org/10.5167/uzh-156342

Journal Article

Published Version

Originally published at:

Iff, Tobias; Meier, Roland; Olah, Eva; Schneider, Jacques F L; Tibussek, Daniel; Berger, Christoph (2005).

Tick-borne meningo-encephalitis in a 6-week-old infant. European Journal of Pediatrics, 164(12):787-788.

DOI: https://doi.org/10.1007/s00431-005-1753-5 


\author{
Tobias Iff · Roland Meier • Eva Olah \\ Jacques F. L. Schneider • Daniel Tibussek \\ Christoph Berger
}

\title{
Tick-borne meningo-encephalitis in a 6-week-old infant
}

Received: 5 April 2005/ Accepted: 23 June 2005 / Published online: 20 August 2005

(C) Springer-Verlag 2005

Tick-borne encephalitis (TBE) in infants is extremely rare $[3,4,5]$. We report a 6 -week-old girl with tick-borne meningo-encephalitis demonstrating that TBE virus (TBEV) has to be considered as a causative agent of meningo-encephalitis in infants in endemic areas.

A 6-week-old girl born at term presented after a 2-day history of fever with vomiting, irritability and a bulging fontanelle. CSF examination showed a pleocytosis (172 lymphocytes, 81 monocytes/ $\mu \mathrm{l})$, elevated protein $(0.83 \mathrm{~g} / \mathrm{l})$, and glucose of $2.4 \mathrm{mmol} / 1$ ( $38 \%$ of serum glucose), and serum C-reactive protein concentration was elevated $(46 \mathrm{mg} / 1)$. Empiric antibiotic treatment was started. Because of a partial, secondary generalised seizure, EEG and MRI were initiated, which demonstrated intermittent slowing in the right parieto-temporal region and T2-weighted cortico-subcortical hyperintensity with contrast enhancement in both fronal lobes and leptomeningeal enhancement, respectively, consistent with diagnosis of meningo-encephalitis (Fig. 1). During the following 3 days, the girl developed repetitive seizures and, accordingly in the EEG, interictal series of sharp waves in the right parieto-temporal region. Treated with phenobarbitone $(5 \mathrm{mg} / \mathrm{kg} /$ day $)$, she became seizure-free and recovered within 9 days. The history of a tickbite on the infant's head 10 days before admission in an endemic area for TBEV in Switzerland prompted us to examine specific TBEV antibodies. The detection of $\operatorname{IgG}$ and $\operatorname{IgM}$ against TBEV in serum, and IgM in CSF established the

T. Iff $(\bowtie) \cdot R$. Meier $\cdot$ D. Tibussek

Division of Neurology, University Children's Hospital,

Steinwiesstrasse 75, 8032 Zürich, Switzerland

E-mail: tobias.iff@ kispi.unizh.ch

Tel.: +41-1-2667111

Fax: +41-1-2667163

E. Olah $\cdot$ C. Berger

Division of Infectious Diseases, University Children's Hospital, Zürich, Switzerland

J. F. L. Schneider

Department of Radiology, University Children's Hospital, Zürich, Switzerland aetiological diagnosis of TBE. Bacterial cultures as well as PCR for herpes simplex virus DNA in CSF and serum antibodies against Borrelia burgdorferi were negative. At the last follow-up at the age of 11 months, the girl's neurological examination, development and EEG were normal.

This 6-week-old infant presenting with meningitis and seizures had meningo-encephalitis with corresponding findings in CSF, EEG and MRI. The history of a tick bite in an endemic area prompted us to check TBEV serology. The detection of TBEV antibodies in serum and CSF established the diagnosis of TBE, after transmission of antibodies from the seronegative mother had been ruled out. In the western parts of Europe including Switzerland, TBE is caused by the western subtype of the TBEV, belonging to the flaviviridae and transmitted predominantly by infected ticks (Ixodes ricinus) in endemic regions [2]. To our knowledge this is the youngest patient with TBE $[2,3,5]$. Although TBE in a 3.5-month-old girl has been reported, the incidence of TBE is lowest in children $<3$ years of age $[3,4,5]$. In children, TBE manifests most commonly as meningitis and runs milder than in adults without or only with transient meningo-encephalitis $[2,4,5]$. The outcome of childhood TBE is generally favourable with complete recovery and no mortality $[2,4,5]$. Nevertheless, preventive measures are crucial because of recently reported rare neurological sequelae in children [1], a reported increase in incidence in Switzerland [6] and the lack of effective therapy [2]. Active vaccination in Switzerland is recommended in endemic areas for children $>6$ years of age with considerable risk of tick-exposure. However, even an extended vaccination policy including younger children ( $>6$ months for selected cases as in Austria) could not have prevented TBE in this patient [4]. Thus, as this young infant with TBE illustrates, exposure prophylaxis, i.e. simple measures for avoiding tickbites and immediate removal of ticks from the body, are the only and most important preventive strategies for infants and young children without the option of active vaccination $[2,6]$. 
Fig. 1 Coronal post-contrast T1-weighted image shows cortical enhancement in both frontal lobes (white arrows) and discrete leptomeningeal enhancement (arrowhead)

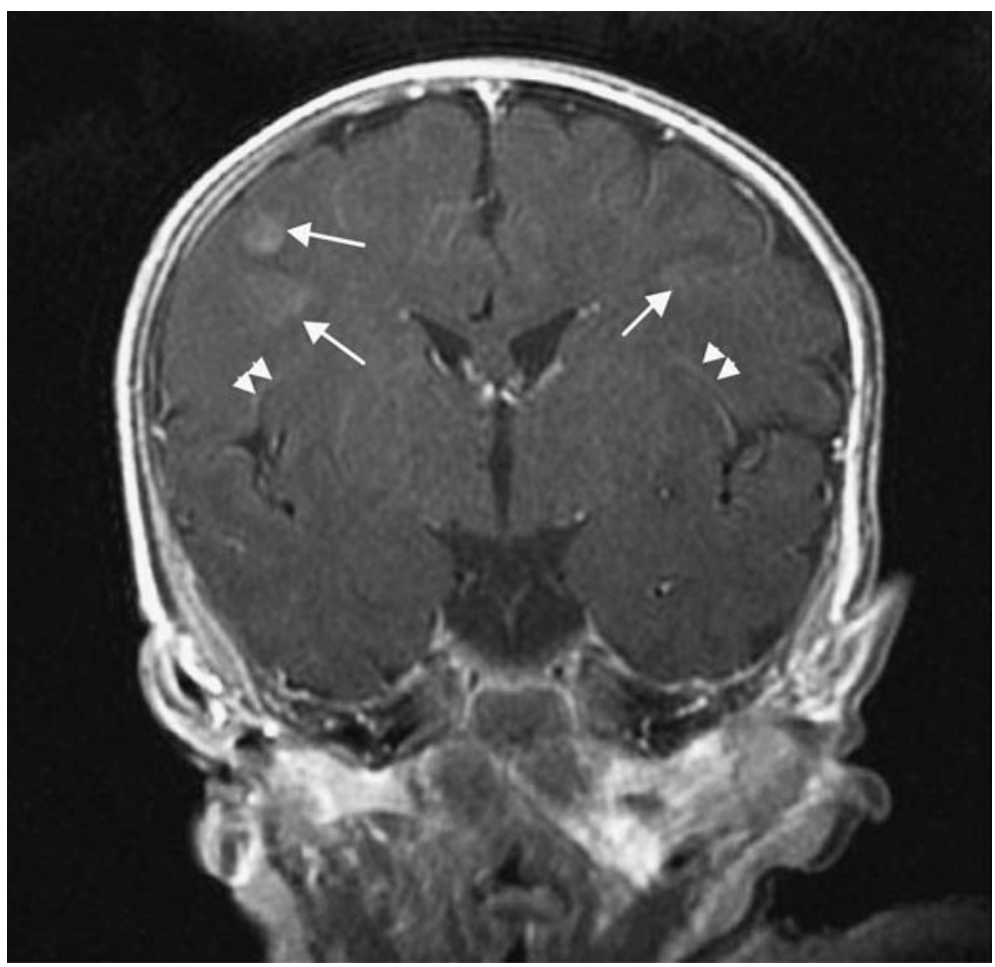

\section{References}

1. Cizman M, Rakar R, Zakotnik B, Pokorn M, Arnez M (1999) Severe forms of tick-borne encephalitis in children. Wien Klin Wochenschr 111: 484-487

2. Dumpis U, Crook D, Oksi J (1999) Tick-borne encephalitis. Clin Infect Dis 28: 882-890

3. Grubbauer HM, Dornbusch HJ, Spork D, Zobel G, Trop M, Zenz W (1992) Tick-borne encephalitis in a 3-month-old child. Eur J Pediatr 151: 743-744

4. Kunze U, Asokliene L, Bektimirov T, Busse A, Chmelik V, Heinz FX, Hingst V, Kadar F, Kaiser R, Kimmig P, Kraigher A, Krech T, Linquist L, Lucenko I, Rosenfeldt V, Ruscio M,
Sandell B, Salzer H, Strle F, Suss J, Zilmer K, Mutz I (2004) Tick-borne encephalitis in childhood-consensus 2004. Wien Med Wochenschr 154: 242-245

5. Lesnicar G, Poljak M, Seme K, Lesnicar J (2003) Pediatric tickborne encephalitis in 371 cases from an endemic region in Slovenia, 1959 to 2000. Pediatr Infect Dis J 22: 612-617

6. Schwanda M, Oertli S, Frauchiger B, Krause M (2000) Tickborne meningoencephalitis in Thurgau Canton: a clinical and epidemiological analysis. Schweiz Med Wochenschr 130: 14471455 